\title{
Influências de um ensino explícito de argumentação no desenvolvimento dos conhecimentos docentes de licenciandos em Química
}

\author{
Influences of the explicit teaching of argumentation \\ on the development of pre-service Chemistry teachers' \\ teaching knowledge
}

Stefannie de Sá Ibraim¹ . Rosária Justi²

\begin{abstract}
Resumo: Objetiva-se analisar como um contexto de ensino explícito de argumentação influenciou o desenvolvimento dos conhecimentos docentes de professores de Química em formação inicial. A coleta de dados ocorreu em uma turma de um curso de Licenciatura em Química com seis licenciandas, a partir de registro em vídeo das aulas e coleta dos materiais escritos produzidos por elas. A análise dos dados indicou que o ensino explícito contribuiu para o desenvolvimento dos conhecimentos docentes das licenciandas devido às oportunidades de: (i) observar as ações da professora formadora enquanto mediadora de situações argumentativas; (ii) mobilizar os conhecimentos de argumentação em situações simuladas de ensino; (iii) trabalhar com materiais didáticos favoráveis à prática argumentativa; e (iv) discutir sobre os elementos referentes à argumentação. Esse trabalho contribui para a pesquisa na área e para a estruturação de programas de formação de professores em argumentação ao apontar aspectos metodológicos que influenciaram o desenvolvimento dos conhecimentos de argumentação das licenciandas.
\end{abstract}

Palavras-chave: Ensino explícito de argumentação. Formação inicial de professores. Conhecimentos docentes em argumentação.

\begin{abstract}
This study aims at analysing how a context of explicit teaching of argumentation influenced the development of chemistry pre-service teachers' knowledge. It was conducted in the context of a subject that comprised a teachers' initial education course. Data were collected from the video recording of the lessons and collection of the written material produced by the six pre-service teachers. Data analysis showed that the explicit teaching contributed to the development of the pre-service teachers' knowledge due to the opportunities of: (i) observing their teacher's actions whilst mediating argumentative situations is several lessons; (ii) using their knowledge of argumentation in simulated lessons; (iii) dealing with didactic materials that support the argumentative practice; and (iv) discussing elements related to argumentation. This study contributes to the research in the area and to the design of teachers' education programmes where it indicates methodological aspects that influenced the development of the pre-service teachers' knowledge on argumentation.
\end{abstract}

Keywords: Explicit teaching of argumentation. Initial teacher training. Teacher's knowledge in argumentation.

\footnotetext{
${ }^{1}$ Universidade Federal de Minas Gerais (UFMG), Faculdade de Educação, Belo Horizonte, MG e Universidade de Brasília, Instituto de Química, Brasília, DF, Brasil. Orcid: < http://orcid.org/0000-0001-5724-993X>. E-mail: <sibraim@unb.br>.

${ }^{2}$ UFMG, Instituto de Ciências Exatas, Departamento de Química, Belo Horizonte, MG, Brasil. Orcid: <http:// orcid.org/0000-0001-6535-5046>.
} 


\section{Introdução}

Os documentos oficiais que regulamentam o ensino básico, tanto no âmbito nacional (por exemplo, BRASIL, 2001) quanto internacional (por exemplo NATIONAL RESEARCH COUNCIL, 2012) têm sustentado o argumento de que o aluno deve ser formado para o exercício da cidadania. Em outras palavras, ao final da escolarização básica, os alunos devem ser capazes de: saber se informar, argumentar, enfrentar problemas de outras naturezas, se engajar em discussões envolvendo aspectos científicos, avaliar as informações científicas relacionadas ao seu cotidiano e continuar a aprender sobre ciências.

Tendo em vista tais objetivos, muitos pesquisadores têm defendido um ensino de ciências mais autêntico (MCNEILL; PIMENTEL, 2010; SAMPSON et al., 2013). Entende-se aqui que ensinar ciências de forma autêntica é oferecer ao aluno a oportunidade de se envolver em práticas científicas de forma que ele possa entender a ciência como ela é (GILBERT, 2004). Isto significa, por exemplo, engajar os alunos em atividades que permitam que desenvolvam investigações, avaliem criticamente suas conclusões e as de seus colegas, comuniquem seus resultados (SAMPSON et al., 2013), se engajem em discussões sobre as ideias dos outros, e possam influenciar a direção do discurso (MCNEILL; PIMENTEL, 2010). Nesse trabalho, defendemos, em especial, o uso da argumentação como suporte para um ensino que envolve as práticas científicas. Isto porque argumentação é uma prática inerente à ciência e se faz presente tanto nos momentos destinados à validação dos modelos e teorias de acordo com os conhecimentos e evidências disponíveis, quanto nos processos de divulgação e legitimação dos conhecimentos científicos produzidos por cientistas (GIERE, 2001).

Em relação ao uso da argumentação no ensino de ciências, muitos pesquisadores da área têm ressaltado resultados positivos em relação ao desenvolvimento de aprendizagem conceitual, visões mais adequadas sobre ciências, e habilidades relacionadas à argumentação (JIMÉNEZ-ALEIXANDRE; PEREIRO MUÑOZ, 2002; MCNEILL; PIMENTEL, 2010; SAMPSON et al., 2013). Por exemplo, Sampson et al. (2013) ao investigarem a relação entre os argumentos escritos e a aprendizagem conceitual dos estudantes ao longo de uma instrução pautada em argumentação, perceberam que, em geral, os estudantes melhoraram o entendimento do conteúdo, o conhecimento sobre as explicações científicas e a habilidade de usá-las em discussões sobre os fenômenos naturais.

Entretanto, ensinar ciências por argumentação exige tanto uma ressignificação nos objetivos do ensino quanto que o professor assuma seu papel como agente responsável pelo desenvolvimento da prática argumentativa em sala de aula. Nesse sentido, Zohar (2008) defende que para que o professor possa atender as demandas de um ensino por argumentação é preciso que ele vivencie (em sua formação inicial ou continuada) práticas argumentativas que favoreçam o desenvolvimento dos conhecimentos e habilidades que auxiliem seu trabalho futuro com argumentação em suas classes de Ciências.

No que diz respeito à formação em argumentação, pesquisadores que têm realizado investigações no âmbito da formação continuada (SIMON; ERDURAN; OSBORNE, 2006) sinalizam que os professores apresentam resistências ao ensino de ciências pautado em argumentação devido ao tempo de aula necessário para que isto seja feito; e às dificuldades em romper com sua prática de ensino ou modificá-la. Por exemplo, Simon, Erduran e Osborne (2006) apontam que apenas os professores que demonstraram boas práticas para o ensino de 
argumentação (por exemplo, encorajar os alunos a falar e a ouvir) no início do processo de formação analisado aperfeiçoaram-nas a partir do engajamento em tal processo de formação. Por outro lado, no âmbito da formação inicial, os licenciandos estão construindo suas identidades enquanto professores da educação básica e têm a oportunidade de ter acesso às discussões mais recentes sobre os objetivos educacionais e estratégias de ensino. Por isso, esses sujeitos tendem a apresentar menos resistência frente a novas perspectivas de ensino do que os professores que estão em exercício há muitos anos e que não participam de programas de formação continuada. Diante disso, nesse trabalho, damos especial atenção às investigações no contexto de formação inicial.

\section{Ensino de argumentação na formação inicial}

O ensino de argumentação na formação de professores pode ocorrer em duas dimensões: implícita e explícita. O ensino implícito de argumentação se refere ao modelo de instrução no qual o sujeito é inserido em um contexto que favorece a argumentação (por exemplo, situações investigativas, discussões sobre questões sociocientíficas etc.). Entretanto, nesse contexto, o professor não vivencia instruções diretas sobre o que é um argumento, sobre como participar da argumentação em sala de aula etc. Nessa perspectiva, é esperado que o conhecimento sobre argumentação e o reconhecimento sobre o papel dessa prática no ensino emerja do próprio contexto.

Baseados na perspectiva implícita de ensino de argumentação, Ozdem et al. (2013) investigaram os argumentos produzidos por professores em formação inicial durante uma investigação orientada em laboratório. Os sujeitos participaram de seis atividades de investigação (orientadas por questões como, por exemplo, qual a relação entre a força aplicada em uma mola e sua deformação?) e não receberam orientações explícitas sobre como construir seus argumentos ou como se engajar em uma discussão científica. As investigações ocorreram em duas partes: experimentação e discussão crítica. Na primeira, os sujeitos planejaram e desenvolveram suas próprias hipóteses, realizaram experimentos, coletaram dados e processaram seus dados para verificar suas hipóteses, isto é, realizaram uma investigação similar à autêntica. Os professores em formação foram encorajados por um dos pesquisadores a discutir as evidências que sustentavam as conclusões apresentadas pelos grupos. Após a discussão, eles tiveram oportunidades de revisar suas hipóteses, experimentos ou interpretações de dados como resultado da discussão. Ao final da experimentação, os grupos prepararam relatórios e apresentações sobre seus resultados. $\mathrm{Na}$ segunda parte - discussão crítica - cada grupo apresentou seus resultados e os demais fizeram questões ou comentários sobre os experimentos ou sobre os resultados. Os autores ressaltam que, ao final do estudo, os professores em formação: ganharam experiências em atividades de investigação em laboratório; tomaram consciência sobre a avaliação dos argumentos à luz das evidências; passaram a reconhecer o papel da argumentação para a aprendizagem; expressaram disposição em integrar argumentação em suas salas de ciências porque acreditavam que a argumentação os encorajou a utilizar evidências e a considerar seu próprio conhecimento; e refletiram sobre suas intenções de adaptar as estratégias utilizadas em suas futuras salas de aulas. Diante desses resultados, os pesquisadores consideraram que aqueles professores podem utilizar os conhecimentos adquiridos nesse processo de formação em suas futuras salas de ciências. 
Tal estudo é um exemplo de ensino implícito de argumentação, pois os professores em formação aprenderam sobre o papel das evidências na avaliação de conclusões e sobre o papel da argumentação a partir do trabalho com experimentos investigativos. Os resultados desta pesquisa nos levam a crer que inserir os professores em formação em contextos de investigação científica pode favorecer a aprendizagem sobre a prática científica, pois além de eles adquirirem experiências com esse tipo de prática, podem ter oportunidades de refletir sobre a mesma. Acreditamos que o contexto vivenciado pelos professores em formação inicial pode ter contribuído para que eles tenham aprendido uma estratégia de ensino que pode favorecer argumentação (nesse caso, o uso de experimentos), porque eles demonstraram interesse em adaptar as atividades em situações de ensino futuras e reconheceram o papel da argumentação para a aprendizagem. Entretanto, apesar desses resultados positivos, pouco podemos dizer sobre como esses futuros professores irão trabalhar com atividades argumentativas em suas salas de ciências, uma vez que nada foi discutido sobre o assunto.

Por outro lado, na perspectiva explícita, os aspectos referentes à prática argumentativa são salientados pelo professor formador. Por exemplo, são ressaltadas as contribuições dessa prática para a aprendizagem dos alunos, as estratégias que podem favorecer a criação de ambientes argumentativos em sala de aula e os elementos que precisam estar presentes nos argumentos. Nessa segunda dimensão do ensino de argumentação, os professores em formação são envolvidos em ambientes que permitem a vivência da prática argumentativa e são conduzidos à reflexão sobre esta.

Ao contrário da abordagem implícita para o ensino de argumentação utilizada por Ozdem et al. (2013), Zembal-Saul (2009) se baseou em uma abordagem explícita para ensinar argumentação na formação inicial de professores de ciências do ensino fundamental. Neste trabalho, ela discute os resultados de pesquisas que investigaram o entendimento de futuros professores sobre o ensino de ciências por argumentação e suas práticas para ensinar nessa perspectiva. Vale ressaltar que o trabalho de Zembal-Saul é um dos poucos dedicados à investigação sobre as contribuições do ensino explícito de argumentação em um contexto de formação inicial. Os sujeitos envolvidos em sua pesquisa participavam de um programa de formação de professores no qual, inicialmente, tinham a chance de vivenciar o ensino de conteúdos de ciências como uma prática científica e de observar o discurso associado ao ensino de ciências por argumentação. Posteriormente, os participantes buscavam na literatura concepções alternativas relacionadas aos conteúdos que seriam ensinados e realizavam entrevistas com os alunos para descobrir suas concepções sobre os tópicos que eles iriam ensinar. Num terceiro momento, eles assistiam, em vídeo, a episódios de ensino que retratavam aspectos particulares do ensino por argumentação (por exemplo, uma discussão entre os alunos na qual eles tentam construir conclusões para suas investigações). Além disso, o professor da turma descrevia as justificativas para as suas ações em sala de aula (por exemplo, o porquê de ele ter tomado certa decisão). Na sequência, levando em consideração as concepções dos alunos, os professores em formação planejavam aulas baseadas no modelo "ensino por argumentação". Esse modelo enfatiza: o uso de atividades investigativas; o uso de argumentos estruturados para orientar a discussão em sala; a explicitação do raciocínio relacionado à formulação de afirmativas a partir da evidência e da avaliação de afirmativas com 
base nas evidências; e o engajamento autêntico na linguagem da ciência. Assim, as atividades planejadas deveriam favorecer o ensino autêntico de ciências. Por último, após aplicar as atividades planejadas, os professores em formação refletiam em grupos sobre os episódios de suas aulas.

Segundo Zembal-Saul (2009), seus resultados indicam que os professores: modificaram suas concepções sobre a investigação no ensino, passando a percebê-la como algo importante; passaram a enfatizar a necessidade de que os alunos coletassem e analisassem os dados e construíssem explicações a partir de evidências; passaram a dar mais importância para as discussões em sala de aula; reconheceram o papel do professor como facilitador do entendimento dos alunos; e começaram a conectar as estratégias do programa com implicações apropriadas em sala de aula. Assim, tal programa de formação de professores em argumentação contribuiu para que os participantes aprendessem sobre a prática científica de argumentar e sobre como abordá-la em sala de aula. Isto porque, além da evolução de suas concepções, eles passaram a solicitar que os alunos trabalhassem com as evidências na análise e construção das afirmativas. Além disso, os fatos de os participantes terem dado mais atenção às discussões em sala e passarem a reconhecer o seu papel de facilitador nos levam a crer que eles reconheciam seu papel no ensino por argumentação.

Embora ambos os trabalhos discutidos anteriormente apontem contribuições do ensino sobre argumentação para a formação de professores, a partir dos resultados de Zembal-Saul (2009) julgamos que o ensino explícito de argumentação favorece a reflexão e o entendimento dos professores sobre como ensinar ciências a partir da argumentação. Isto porque, nessa perspectiva, os professores em formação aprendem o que é um argumento e sobre o processo de argumentação, além de serem convidados a trabalhar com atividades focadas em argumentação e a refletir sobre essa experiência.

Entretanto, apesar de o trabalho de Zembal-Saul apresentar evidências relacionadas às contribuições do ensino explícito de argumentação na formação inicial de professores de ciências, a autora não discute como a metodologia adotada contribuiu para o desenvolvimento dos conhecimentos em argumentação dos professores em formação. Consideramos que esta seja uma discussão importante para a área e para a estruturação de futuros programas de formação de professores, pois ela pode indicar contribuições e/ou limitações de aspectos metodológicos utilizados em programas de formação de professores em argumentação.

\section{Questão de pesquisa}

Considerando (i) o fato de os professores, no contexto de formação inicial, tenderem a apresentar menos resistência frente a novas perspectivas de ensino; (ii) as contribuições da perspectiva explícita para a formação de professores em argumentação; e (iii) a necessidade de discutir a relação entre os aspectos metodológicos utilizados no ensino explícito de argumentação e o desenvolvimento dos conhecimentos docentes em argumentação, buscamos contribuir com a literatura da área ao investigarmos a seguinte questão de pesquisa: Como um programa de formação inicial direcionado ao ensino explicito de argumentação pode influenciar o desenvolvimento dos conhecimentos em argumentação de professores de Química em formação inicial? 


\section{Metodologia}

\section{Contexto e coleta de dados}

O programa de formação inicial de professores no qual ocorreu o ensino explícito de argumentação investigado nesse trabalho corresponde a uma disciplina ministrada aos alunos do último período de um curso de Licenciatura em Química de uma universidade pública do sudeste do Brasil ${ }^{3}$. Essa disciplina foi ministrada por uma professora graduada em Química, mestre e doutora na área de Ensino de Ciências e foi cursada por seis professores em formação, todas do sexo feminino. Neste trabalho, elas são identificadas por nomes fictícios: Gisele, Isis, Lara, Letícia, Maria e Rafaela.

A disciplina cursada pelas licenciandas envolveu a discussão dos tópicos: argumentação, atividades investigativas, e experimentação no Ensino de Química. Embora, o tópico argumentação constituísse um dos conteúdos da disciplina, discussões envolvendo argumentação permearam as discussões dos demais tópicos, pois a professora buscou discutir como um ambiente argumentativo poderia ser criado ou favorecido a partir das estratégias de ensino investigativas e por meio da experimentação.

Todas as aulas ocorridas durante o programa de formação foram observadas e registradas em vídeo. Durante o ensino explícito de argumentação, as licenciandas produziram dois planos de aulas simuladas (isto é, que elas conduziram na própria disciplina, tendo os colegas e outros licenciandas do curso como 'alunos'). Um deles envolveu explicitamente a argumentação e outro envolveu todos os conteúdos discutidos na disciplina (argumentação, atividades investigativas e experimentação). Consideramos importante coletar esses planos de aula, pois eles poderiam ser fonte de informações do conhecimento sobre argumentação das licenciandas.

\section{Análise de dados}

Todas as aulas foram descritas detalhadamente e os diálogos ocorridos durante as discussões das atividades sobre argumentação foram transcritos. De posse das transcrições dos dados e de sua organização em ordem cronológica, construímos um estudo de caso que descreve os processos de ensino e aprendizagem relacionados à argumentação ocorridos naquele contexto. A construção do caso teve por objetivo apresentar as atividades e textos discutidos durante o período de ensino; destacar as ações e falas da professora que possam ter contribuído para a aprendizagem das licenciandas; e salientar as manifestações das mesmas relacionadas às dificuldades de aprendizagem e ao desenvolvimento do conhecimento relativo à argumentação.

\footnotetext{
${ }^{3}$ Este curso é dividido em oito períodos com duração de 4 meses cada. Nos primeiros quatro períodos, os alunos cursam disciplinas direcionadas ao desenvolvimento do conteúdo químico e de outros conteúdos científicos (física, matemática etc.). Do quinto ao oitavo período, os alunos continuam a cursar disciplinas de conteúdo químico, mas também cursam disciplinas de conhecimento pedagógico geral e disciplinas de conteúdo pedagógico específico para o ensino de Química.
} 
Inicialmente, considerando o estudo de caso, analisamos o desenvolvimento dos conhecimentos das licenciandas relativos à argumentação a partir do modelo conhecimento para ação docente em argumentação (IBRAIM; JUSTI, 2016). Esse modelo, que expressa nossa visão de argumentação, apresenta um conjunto de conhecimentos, os quais são considerados necessários para que os futuros professores possam conduzir situações de ensino de ciências pautadas em argumentação. Nesse sentido, ele envolve elementos relacionados a:

- o entendimento do professor sobre a natureza da prática argumentativa. Isto envolve conhecimentos de (i) estrutura básica do argumento: evidência, justificativa e conclusão (TOULMIN, 1958); (ii) capacidades argumentativas de elaborar argumentos e teorias alternativas, contra argumentar e refutar (KUHN, 1991); e (iii) compreensão dos principais propósitos das situações argumentativas: estabelecimento de consenso e persuasão (JIMENÉZ-ALEIXANDRE, 2010); e

- o conhecimento sobre aspectos pedagógicos relacionados ao ensino baseado em argumentação, isto é, conhecimentos sobre estratégias de ensino, materiais instrucionais e ações que favorecem o ensino pautado em argumentação, assim como habilidades para conduzir situações argumentativas (IBRAIM; JUSTI, 2016).

O estudo no qual o modelo conhecimento para ação docente em argumentação foi proposto (IBRAIM; JUSTI, 2016), aponta que o ensino de argumentação vivenciado pelas licenciandas contribuiu para que as mesmas começassem a desenvolver seus conhecimentos docentes relativos à prática argumentativa. Frente a este resultado, julgamos importante investigar os aspectos metodológicos relacionados ao programa de formação inicial em argumentação que podem ter contribuído para o desenvolvimento desse conhecimento por parte das licenciandas.

A fim de responder nossa questão de pesquisa, buscamos identificar as possíveis influências de aspectos metodológicos específicos do ensino explícito de argumentação no desenvolvimento dos conhecimentos dos professores em formação relatados no modelo conhecimento para ação docente em argumentação. Inicialmente, o processo de análise foi realizado pela primeira autora, que buscou identificar os momentos nos quais a professora formadora ensinou algum aspecto relacionado aos conhecimentos docentes em argumentação e em que as licenciandas manifestaram alguma compreensão ou dúvidas relativas ao entendimento desses aspectos. Essa análise foi baseada em observação em sala de aula, nas falas das licenciandas e da professora formadora (registradas em vídeo) e em outras fontes de dados como, por exemplo, os materiais utilizados pela professora e os produzidos pelas licenciandas. Em seguida, as duas autoras discutiram e negociaram quaisquer inconsistências presentes na análise. Portanto, o processo de triangulação foi realizado a partir do uso de múltiplas fontes de dados e pela participação de duas pesquisadoras.

Ao analisar o estudo de caso e as discussões provenientes dele, observamos que as influências do ensino explícito foram provenientes tanto das ações da professora formadora durante o processo de ensino quanto da forma como a disciplina foi organizada por ela - o que inclui os materiais selecionados e sua organização e a estrutura da disciplina como um todo. A partir dessa análise, construímos o Quadro 1, que apresenta alguns aspectos referentes ao processo de ensino em argumentação. Os aspectos apontados no Quadro 1 se referem tanto às ações pontuais da professora e das licenciandas quanto a observações feitas em cada aula. Por fim, apresentamos as discussões em termos das fontes de influências. Porém, destacamos que o processo de ensino é dinâmico, ou seja, não existe tal separação: as fontes são interdependentes e estreitamente relacionadas. 


\section{Resultados e discussões}

No Quadro 1, apresentamos alguns aspectos que caracterizam o processo de ensino -aprendizagem ocorrido na disciplina relativos à argumentação (tanto em termos das atividades quanto dos eventos ocorridos). Eles se relacionaram tanto às aulas específicas sobre argumentação (1 a 12) quanto a algumas aulas ocorridas no final da disciplina.

Quadro 1. Aspectos referentes ao processo de ensino em argumentação

\begin{tabular}{|c|c|c|}
\hline Aulas & Atividade & Observações mais relevantes sobre as aulas \\
\hline 1 & $\begin{array}{l}\text { Discussão da atividade } \\
\text { 'Halloween Crush' (ERDURAN; } \\
\text { PABUCCU, 2012) (Atividade } \\
\text { 1), na qual é apresentado o caso } \\
\text { de um grupo de jovens em uma } \\
\text { cabana que foi surpreendido por } \\
\text { um acidente envolvendo uma } \\
\text { lata de azeite, seguido de duas } \\
\text { questões ("Por que a tampa da } \\
\text { lata explodiu?" e "Por que a lata } \\
\text { amassou?"), assim como de uma } \\
\text { lista de razões que poderiam ser } \\
\text { usadas para respondê-las. As } \\
\text { licenciandas deveriam avaliar as } \\
\text { razões como "mais relevante" e } \\
\text { "menos relevante" e justificar as } \\
\text { escolhas. }\end{array}$ & $\begin{array}{l}\text { - A partir da discussão da atividade 1, a professora } \\
\text { destacou características dos materiais direcionados à } \\
\text { argumentação explícita (por exemplo, solicitar a análise } \\
\text { de evidências) e chamou atenção para as características } \\
\text { essenciais aos materiais instrucionais que podem } \\
\text { favorecer a argumentação. } \\
\text { - Retomando a discussão das respostas dadas pelas } \\
\text { licenciandas à atividade 1, a professora discutiu com } \\
\text { elas sobre justificativas e análise dos dados. Isis e } \\
\text { Rafaela manifestaram dificuldades em relação ao } \\
\text { entendimento do conceito de justificativa. Nesses } \\
\text { momentos, a professora retomou o conceito de } \\
\text { justificativa diferenciando-o do de evidência e as demais } \\
\text { colegas utilizaram exemplos para explicar o conceito de } \\
\text { justificativas para a dupla. } \\
\text { - Ao serem solicitadas a apresentar características } \\
\text { essenciais aos materiais, todas as licenciandas } \\
\text { destacaram que o problema deveria: apresentar mais } \\
\text { de uma variável, ser aberto, e possibilitar múltiplas } \\
\text { interpretações. }\end{array}$ \\
\hline 2 & $\begin{array}{l}\text { Discussão do texto 1: Argumentar } \\
\text { consiste en evaluar los enunciados } \\
\text { en base a pruebas (JIMÉNEZ- } \\
\text { ALEIXANDRE, 2010), } \\
\text { que discute o significado de } \\
\text { argumentação e de argumentos } \\
\text { de autoridade, a possibilidade } \\
\text { de múltiplas interpretações das } \\
\text { evidências, e a argumentação } \\
\text { como um processo social. }\end{array}$ & $\begin{array}{l}\text { - A professora formadora discutiu os aspectos de } \\
\text { argumentação abordados no texto } 1 \text { e salientou a } \\
\text { importância de professores utilizarem questões abertas } \\
\text { para engajar os alunos no ensino por argumentação. } \\
\text { - Ao ser questionada pela professora sobre a leitura } \\
\text { do texto, Maria afirmou que (i) a partir da leitura, ela } \\
\text { reconheceu a possibilidade de apresentar evidências } \\
\text { para os conhecimentos científicos ensinados nas } \\
\text { aulas de ciências; e (ii) ela não tinha pensado sobre tal } \\
\text { possibilidade antes. }\end{array}$ \\
\hline
\end{tabular}


Quadro 1. continuação

\begin{tabular}{|c|c|c|}
\hline Aulas & Atividade & Observações mais relevantes sobre as aulas \\
\hline 3 & $\begin{array}{l}\text { Discussão da atividade 2: Por } \\
\text { que nós sabemos o que sabemos? } \\
\text { (JIMÉNEZ-ALEIXANDRE et } \\
\text { al., 2009). Nela, são apresentadas } \\
\text { diversas afirmativas relacionadas } \\
\text { a conteúdos químicos (por } \\
\text { exemplo, água salgada é uma } \\
\text { mistura), para as quais devem } \\
\text { ser apresentadas evidências e } \\
\text { justificativas. }\end{array}$ & $\begin{array}{l}\text { - A partir da discussão da atividade 2, a professora } \\
\text { reforçou os conceitos de evidências e justificativas } \\
\text { e ressaltou o papel de evidências específicas. Além } \\
\text { disso, ela chamou atenção para uma característica dos } \\
\text { materiais favoráveis à argumentação: a possibilidade de } \\
\text { respostas não consensuais. } \\
\text { - Inicialmente, durante a realização da atividade 2, todas } \\
\text { as licenciandas manifestaram dificuldades em propor/ } \\
\text { identificar evidências para as afirmativas químicas e } \\
\text { em perceber se uma dada evidência era suficiente ou } \\
\text { específica para uma afirmativa. } \\
\text { - Ao serem questionadas pela professora sobre quais } \\
\text { características de uma atividade podem favorecer a } \\
\text { argumentação, as licenciandas responderam dizendo que } \\
\text { a atividade precisava: apresentar variáveis; se originar } \\
\text { de um problema que não tivesse solução única; e } \\
\text { possibilitar a proposição de várias justificativas. }\end{array}$ \\
\hline 4 & $\begin{array}{l}\text { Discussão do texto 2: } L a \\
\text { argumentación contribuye a } \\
\text { competencias básicas y objetivos } \\
\text { generales de la educació (JIMÉNEZ- } \\
\text { ALEIXANDRE, 2010), no qual } \\
\text { são abordadas as contribuições } \\
\text { da prática argumentativa para a } \\
\text { aprendizagem "sobre ciência" } \\
\text { e "de ciências", e para o } \\
\text { desenvolvimento do raciocínio } \\
\text { crítico dos alunos. }\end{array}$ & $\begin{array}{l}\text { - Relembrando a atividade 1, a professora ressaltou a } \\
\text { importância das questões utilizadas por ela para engajar } \\
\text { as licenciandas na argumentação. } \\
\text { - Ao serem questionadas pela professora sobre } \\
\text { como favorecer o desenvolvimento da argumentação } \\
\text { em sala de aula, todas as licenciandas apontaram as } \\
\text { características e a importância dos materiais utilizados } \\
\text { para fomentar argumentação em sala de aula. }\end{array}$ \\
\hline 5 & $\begin{array}{l}\text { Realização da atividade 3: } \\
\text { "Crânio de Copérnico" } \\
\text { JIMÉNEZ-ALEIXANDRE, } \\
\text { 2010). Ela é composta por um } \\
\text { texto no qual são apresentados } \\
\text { dados que devem ser usados para } \\
\text { dizer se um crânio encontrado } \\
\text { pertencia ou não a Copérnico. }\end{array}$ & $\begin{array}{l}\text { - A partir da discussão da atividade } 3 \text {, a professora } \\
\text { destacou a característica principal do material: o } \\
\text { uso de texto que apresenta dados que precisam ser } \\
\text { interpretados. } \\
\text { - A partir das discussões sobre evidências específicas, } \\
\text { Maria relatou que teve dificuldades em mobilizar esse } \\
\text { tipo de evidência na atividade } 2 \text {, pois ela não conseguia } \\
\text { perceber se a evidência apresentada por ela era } \\
\text { específica ou suficiente para o caso. }\end{array}$ \\
\hline
\end{tabular}

\footnotetext{
${ }^{4} \mathrm{O}$ material utilizado pela professora foi uma adaptação dessa atividade por apresentar apenas afirmativas químicas.
} 
Quadro 1. continuação

\begin{tabular}{|c|c|c|}
\hline Aulas & Atividade & Observações mais relevantes sobre as aulas \\
\hline 6 & $\begin{array}{l}\text { Discussão do texto 3: Los } \\
\text { criterios para evaluar pruebas incluyen } \\
\text { especificidad, suficiencia, fiabilidad } \\
\text { (JIMÉNEZ-ALEIXANDRE, } \\
\text { 2010). O foco principal é a } \\
\text { discussão sobre a interpretação } \\
\text { das evidências, a qual envolve os } \\
\text { critérios usados para avaliá-las. } \\
\text { Nesse sentido, são abordados } \\
\text { o significado de confiabilidade, } \\
\text { validade e especificidade de uma } \\
\text { evidência. }\end{array}$ & $\begin{array}{l}\text { - A professora discutiu o texto } 3 \text { e estabeleceu relações } \\
\text { entre o texto e a atividade } 3 \text {, na qual nenhum dado } \\
\text { poderia ser usado como uma evidência específica para } \\
\text { o caso. } \\
\text { - Durante a discussão sobre o texto } 3 \text {, Lara disse que } \\
\text { nenhuma evidência apresentada na aula } 5 \text { (atividade } 3 \text { ), } \\
\text { poderia ser considerada específica, pois todas permitiam } \\
\text { refutação. }\end{array}$ \\
\hline 7 & $\begin{array}{l}\text { Realização da atividade 4: } \\
\text { "Bonecos de neve"5 (OSBORNE; } \\
\text { ERDURAN; SIMON, 2004). } \\
\text { Nela, é apresentado um problema } \\
\text { científico no qual as licenciandas } \\
\text { deveriam escolher, entre duas } \\
\text { possibilidades, a resposta que } \\
\text { julgavam correta. O problema } \\
\text { também envolvia questões que } \\
\text { favoreciam a expressão das } \\
\text { capacidades argumentativas } \\
\text { elaboração de argumentos, } \\
\text { proposição de teoria alternativa, } \\
\text { contra argumentação e refutação. }\end{array}$ & $\begin{array}{l}\text { - A partir da socialização das respostas à atividade } 4 \text {, } \\
\text { a professora discutiu o significado das capacidades } \\
\text { argumentativas apresentadas na mesma. } \\
\text { - Ao final da aula, ao serem questionadas pela } \\
\text { professora se havia ficado claro o que são as capacidades } \\
\text { argumentativas, todas as licenciandas afirmaram ter } \\
\text { entendido os aspectos relacionados a capacidades } \\
\text { argumentativas envolvidos na atividade. }\end{array}$ \\
\hline 8 & $\begin{array}{l}\text { Discussão do texto 4: La } \\
\text { argumentación socio científica } \\
\text { contribuye al pensamiento crítico } \\
\text { (JIMÉNEZ-ALEIXANDRE, } \\
\text { 2010), que aborda o significado } \\
\text { de questões sociocientíficas } \\
\text { e suas contribuições para o } \\
\text { desenvolvimento do raciocínio } \\
\text { crítico, a aprendizagem sobre } \\
\text { ciências, e a tomada de decisões. }\end{array}$ & $\begin{array}{l}\text { - A professora discutiu os aspectos salientados no } \\
\text { texto } 4 \text { e destacou as contribuições do uso de questões } \\
\text { sociocientíficas para a formação de cidadãos críticos e } \\
\text { aprendizagem de aspectos de natureza da ciência. } \\
\text { - Ao serem questionadas pela professora sobre o } \\
\text { desenvolvimento da argumentação nos diferentes } \\
\text { contextos, as licenciandas relacionaram a argumentação } \\
\text { científica à atividade } 4 \text { e reconheceram que a atividade } \\
3 \text { não poderia ser classificada como científica ou como } \\
\text { sociocientífica, pois não envolvia, necessariamente, } \\
\text { conhecimento científico. }\end{array}$ \\
\hline
\end{tabular}

continua

\footnotetext{
${ }^{5} \mathrm{O}$ material trabalhado em sala pela professora foi uma adaptação dessa atividade. Diferente do material original, o novo material apresentava questões baseadas nas capacidades argumentativas apresentadas por Kuhn (1991).
} 
Quadro 1. continuação

\begin{tabular}{|c|c|c|}
\hline Aulas & Atividade & Observações mais relevantes sobre as aulas \\
\hline 9 e 10 & $\begin{array}{l}\text { Planejamento, em duplas, de } \\
\text { aulas simuladas que favorecessem } \\
\text { explicitamente a ocorrência de } \\
\text { argumentação e discussão do } \\
\text { planejamento. }\end{array}$ & $\begin{array}{l}\text { - Durante o planejamento, a professora sugeriu que a } \\
\text { dupla Rafaela e Lara utilizasse a estratégia de simulação } \\
\text { de papéis no ensino. }\end{array}$ \\
\hline 11 & $\begin{array}{l}\text { Apresentação de aula simulada } \\
1 \text { pelas duplas: Rafaela e Lara, } \\
\text { Letícia e Gisele. }\end{array}$ & $\begin{array}{l}\text { - Lara e Rafaela elaboraram um texto que apresentava } \\
\text { dados que poderiam ser usados para dar suporte a } \\
\text { argumentos a favor e contra o uso de sacolas plásticas. Elas } \\
\text { sugeriram que fosse realizado um júri simulado envolvendo } \\
\text { os dois posicionamentos para discutir a questão. } \\
\text { - Gisele e Letícia elaboraram uma atividade que apresentava } \\
\text { um caso de um adolescente que desejava emagrecer e } \\
\text { precisava escolher uma entre três dietas apresentadas. Ao } \\
\text { longo da atividade, eram apresentadas informações sobre } \\
\text { as dietas que poderiam ser utilizadas na construção de } \\
\text { argumentos a favor ou contra o uso das mesmas. Ao final } \\
\text { da atividade, era solicitado que fosse proposta uma dieta } \\
\text { alternativa. } \\
\text { - Lara e Rafaela elaboraram um texto que apresentava } \\
\text { poucas evidências. Além disso, Lara manifestou dificuldades } \\
\text { em diferenciar evidências de justificativas durante a } \\
\text { proposição de um argumento. } \\
\text { - Em sua proposta, Letícia e Gisele apresentaram dados } \\
\text { que poderiam ser usados como evidência durante a análise } \\
\text { das dietas e utilizaram adequadamente o conceito de } \\
\text { justificativas nas questões propostas. } \\
\text { - A atividade elaborada por Letícia e Gisele possibilitava } \\
\text { múltiplas respostas à questão problema. } \\
\text { - As duas duplas elaboraram uma atividade envolvendo } \\
\text { uma questão sociocientífica. }\end{array}$ \\
\hline 12 & $\begin{array}{l}\text { Apresentação de aula simulada } 1 \\
\text { pela dupla Maria e Isis. }\end{array}$ & $\begin{array}{l}\text { - A atividade elaborada pela dupla era composta por } \\
\text { uma história em quadrinhos que relatava o caso de uma } \\
\text { adolescente que realizou um processo de alisamento no } \\
\text { cabelo e, depois de alguns dias, observou que os fios do } \\
\text { seu cabelo haviam se quebrado. Na atividade também } \\
\text { eram apresentadas informações sobre a substância } \\
\text { formol (geralmente utilizada no processo de alisamento } \\
\text { de cabelos) e o fato de a adolescente ter entrado em } \\
\text { contado com a água do mar e ter ficado exposta ao sol. } \\
\text { As questões propostas favoreciam a manifestação das } \\
\text { capacidades argumentativas discutidas anteriormente. }\end{array}$ \\
\hline
\end{tabular}

continua 
Quadro 1. continuação

\begin{tabular}{|c|c|c|}
\hline Aulas & Atividade & Observações mais relevantes sobre as aulas \\
\hline 25 & $\begin{array}{l}\text { Apresentação de aula simulada } 2 \\
\text { por Isis e Rafaela. }\end{array}$ & $\begin{array}{l}\text { - Isis e Rafaela construíram uma atividade experimental } \\
\text { envolvendo o fenômeno de cromatografia em papel. } \\
\text { O experimento consistia em realizar a cromatografia } \\
\text { de três pigmentos: azul, verde e roxo. A dupla utilizou } \\
\text { como solvente a água e os pigmentos eram retirados de } \\
\text { doces }{\mathrm{M} \& \mathrm{M}^{\circledR}}^{\circledR} \text { usando um pincel molhado. } \\
\text { - Durante a atividade, a dupla destacou os dados que } \\
\text { poderiam ser usados como evidências (por exemplo, o } \\
\text { fato de o M\&M}{ }^{\circledR} \text { seco não transferir a cor para o papel). } \\
\text { - A dupla utilizou de forma adequada o conceito de } \\
\text { justificativa nas questões propostas na atividade e } \\
\text { realizou questionamentos com a intenção de engajar os } \\
\text { alunos na prática argumentativa. }\end{array}$ \\
\hline $26^{6}$ & $\begin{array}{l}\text { Apresentação de aula simulada } 2 \\
\text { por Gisele. }\end{array}$ & $\begin{array}{l}\text { - Gisele propôs que a propriedade coligativa ebulioscopia } \\
\text { fosse discutida a partir de uma atividade experimental. A } \\
\text { atividade envolvia a preparação de café e, a partir disso, os } \\
\text { participantes deveriam propor modelos que explicassem } \\
\text { o que estava acontecendo durante o preparo da bebida. } \\
\text { Gisele propôs que as capacidades argumentativas fossem } \\
\text { trabalhadas a partir da proposição de modelos e discussão } \\
\text { dos mesmos. A partir das discussões da atividade, a } \\
\text { licencianda introduziu o conceito de ebulioscopia. } \\
\text { - Gisele apresentou as evidências relacionadas ao } \\
\text { fenômeno investigado e as utilizou para dar suporte } \\
\text { às afirmativas científicas. Porém, ela não discutiu as } \\
\text { evidências mobilizadas pelos participantes da aula } \\
\text { simulada. } \\
\text { - Gisele utilizou de forma adequada o conceito de } \\
\text { justificativa nas questões propostas na atividade e, durante } \\
\text { a discussão, apresentou justificativas que davam suporte } \\
\text { às evidências. Ela também solicitou que os alunos da } \\
\text { aula simulada apresentassem suas justificativas para as } \\
\text { observações feitas. } \\
\text { - O material produzido possibilitava a manifestação de } \\
\text { diferentes respostas e a coleta de dados que deveriam ser } \\
\text { analisados na construção de evidências para dar suporte à } \\
\text { proposição dos modelos. }\end{array}$ \\
\hline
\end{tabular}

continua

\footnotetext{
${ }^{6}$ Nas aulas 13 a 24 foram discutidos os tópicos atividades investigativas e experimentação no Ensino de Química. Em duplas, as licenciandas planejaram aulas simuladas que deveriam envolver os três aspectos discutidos na disciplina: atividades investigativas, experimentação e argumentação. Os planejamentos foram discutidos com a professora.

${ }^{7}$ Maria não participou das aulas simuladas finais e, por isso, Gisele ministrou a aula sozinha.
} 
Quadro 1. continuação

\begin{tabular}{|l|l|l|}
\hline Aulas & \multicolumn{1}{|c|}{ Atividade } & \multicolumn{1}{c|}{ Observações mais relevantes sobre as aulas } \\
\hline 27 & Apresentação de aula simulada 2 & - Letícia e Lara elaboraram uma atividade experimental \\
nor Lara e Letícia. & $\begin{array}{l}\text { naul era confeccionado um calorímetro e realizada } \\
\text { a queima de dois alimentos: amendoim e castanha } \\
\text { do Pará. A partir dos resultados encontrados no } \\
\text { experimento, elas discutiram o significado de caloria e a } \\
\text { ocorrência de erros experimentais. } \\
\text { - Durante a discussão da atividade, a dupla destacou } \\
\text { quais dados poderiam ser utilizados como evidências na } \\
\text { discussão sobre a discrepância entre o resultado teórico } \\
\text { e o experimental. } \\
\text { - Lara e Letícia utilizaram de forma adequada o } \\
\text { conceito de justificativa nas questões propostas na } \\
\text { atividade e solicitaram que os participantes da simulação } \\
\text { apresentassem suas justificativas para os procedimentos. } \\
\text { • O material produzido possibilitava a manifestação de } \\
\text { diferentes respostas e a coleta de dados que deveriam } \\
\text { ser analisados na construção de evidências para } \\
\text { sustentar as conclusões experimentais. }\end{array}$ \\
\hline
\end{tabular}

Fonte: elaborado pelas autoras.

A análise dos dados evidenciou que as ações adotadas pela professora formadora, bem como o fato de ela destacar suas ações e seus questionamentos durante as discussões das atividades argumentativas, influenciaram o desenvolvimento dos conhecimentos relativos à argumentação das licenciandas sobre como criar e conduzir um ambiente argumentativo em sala de aula. Em outras palavras, tais ações impactaram, principalmente, no desenvolvimento dos conhecimentos das licenciandas relacionados às estratégias de ensino, materiais instrucionais e habilidades favoráveis para conduzir situações argumentativas no contexto de ensino. Por exemplo, na aula 2, a professora questionou as licenciandas com o intuito de estabelecer consenso entre a ordenação das razões apresentadas na atividade para justificar um fenômeno. $\mathrm{Na}$ aula seguinte, ela ressaltou as ações que havia realizado durante a discussão da atividade 2 para ajudar as licenciandas a expressar suas justificativas, estabelecer consenso etc., e ressaltou a possibilidade de, em algumas atividades, poder haver mais de uma resposta adequada. Um indício dessa influência no desenvolvimento do conhecimento das licenciandas é fato de todas terem conseguido formular questões abertas de forma a favorecer o engajamento dos participantes na prática argumentativa tanto durante as aulas simuladas quanto nas questões apresentadas nos materiais. Por exemplo, na aula simulada final (aula 27, Quadro 1), ao longo de toda a atividade, Letícia e Lara solicitaram aos alunos que justificassem suas respostas. Isto foi feito a partir de questões como, por exemplo: "Você envolveu o alimento com uma lata. Havia necessidade de usar essa lata? Se sim, por quê?”.

Uma segunda influência diz respeito às intervenções que a professora realizou nos momentos nos quais as licenciandas manifestaram dúvidas ou limitações em algum dos conhecimentos. Nesses casos, as ações da professora foram direcionadas ao reforço do conceito ou à 
discussão sobre o uso de determinado elemento no processo argumentativo. Constatamos que essas discussões influenciaram o desenvolvimento dos conhecimentos conceituais relativos à argumentação das licenciandas, em especial, o conhecimento sobre evidências e justificativas, pois elas tiveram várias oportunidades de discutir sobre os conhecimentos e sobre o porquê de suas respostas. Por exemplo, na aula 1, na qual foi discutida a atividade 1, a professora apresentou o conceito de justificativa, mas Isis e Rafaela tiveram dificuldades para entendê-lo. Então, sempre que as alunas manifestavam tal dificuldade, a professora intervinha reforçando o conceito de justificativa ou a diferença entre justificativa e os demais elementos de um argumento. Isto contribuiu para que, ao final dessa aula, Isis e Rafaela conseguissem apresentar uma conclusão sobre o significado de justificativa, afirmando que a justificativa se referia ao porquê de ter ocorrido a explosão da tampa da lata de azeite.

Outra influência se refere à promoção de momentos destinados à socialização das respostas das atividades realizadas. Após as licenciandas realizarem as atividades, a professora propunha um momento de discussão no qual todas expressavam suas respostas e analisavam as respostas das colegas. Tais momentos influenciaram principalmente o desenvolvimento do conhecimento sobre argumentação das licenciandas em relação à evidência e justificativa, pois permitiram que elas participassem do processo de regulação de sua aprendizagem. Por exemplo, na aula 5, Maria disse que, em alguns momentos, todas elas se confundiram ao tentar apresentar evidências e justificativas na atividade $2 \mathrm{e}$, por isso, foi importante ter um momento de discussão das respostas para que pudessem tomar consciência de seus conhecimentos sobre evidências e justificativas e para que a ênfase nesses elementos não passe despercebida nas aulas.

Além das influências relacionadas diretamente às ações da professora, concluímos que a maneira como a disciplina foi organizada e os materiais selecionados também influenciaram o desenvolvimento dos conhecimentos das licenciandas relativos à argumentação. Isto porque o ensino de argumentação foi planejado de forma que as licenciandas tivessem várias oportunidades de vivenciar atividades argumentativas seguidas da discussão de um texto relacionado à atividade. Por exemplo, a atividade 3 envolvia a discussão sobre a suficiência e especificidade de evidências e o texto 4, discutido em seguida, favorecia discussões sobre esses aspectos das evidências. Tal opção metodológica geral oportunizou a discussão dos conceitos mobilizados tanto nas atividades quanto a partir dos textos, favorecendo também a reflexão sobre a importância deles para o processo argumentativo. Além disso, a opção metodológica da professora permitiu discutir diferentes aspectos de um mesmo conhecimento por meio de várias atividades e retomar a discussão sobre os conhecimentos ao longo da disciplina, o que influenciou o desenvolvimento dos conhecimentos das licenciandas relativos à natureza da prática argumentativa. Um indício dessa influência é o fato de, ao longo da disciplina, as licenciandas manifestarem menos dúvidas sobre o elemento evidência e conseguirem estabelecer relações entre as discussões dos textos e as atividades realizadas. Por exemplo, durante a discussão sobre os exemplos apresentados no texto 3 e as evidências mobilizadas para cada exemplo, a professora ressaltou que os dados relativos aos índices de câncer de pulmão não eram evidências específicas para a relação entre consumo de cigarro e câncer de pulmão porque permitam a ocorrência de refutações. Nesse momento, Lara disse que, assim como nesse caso, nenhuma das evidências apresentada na atividade 3 ("Crânio de Copérnico", aula 5) seria específica, pois todas elas permitiam refutação.

Além disso, o uso de várias atividades relacionadas à argumentação favoreceu o acesso das licenciandas aos diferentes tipos de materiais que podem dar suporte à criação de ambientes 
argumentativos em sala de aula. Nesse caso, concluímos que a opção metodológica de envolver as licenciandas em diferentes atividades argumentativas influenciou seus conhecimentos sobre materiais instrucionais. Uma evidência dessa influência são os materiais instrucionais elaborados por elas para a primeira aula simulada. Embora tivessem acesso a outros materiais, diferentes dos que foram utilizados em sala, elas optaram por basear suas propostas nos materiais utilizados pela professora em sala de aula. Por exemplo, Lara e Rafaela, produziram um texto que apresentava dados que poderiam ser utilizados como evidências a favor ou contra o uso de sacolas biodegradáveis, ou seja, dados que não eram específicos a um posicionamento (aula 11, Quadro 1). Como relatado pelas licenciandas, elas criaram esse texto baseado no texto da atividade 3 , no qual os dados podem dar suporte à uma afirmativa ou à uma negativa para o fato de o crânio encontrado pertencer a Copérnico.

O ensino explícito de argumentação permitiu que as licenciandas discutissem sobre argumentação tanto no contexto científico quanto no contexto sociocientífico. As discussões sobre argumentação relacionadas ao âmbito científico ocorreram por meio de atividades (por exemplo, a 4, aula 7, Quadro 1) e contemplaram aspectos como: o que conta como evidência para o conhecimento científico, a importância das justificativas para dar suporte às afirmativas etc. Por outro lado, grande parte das discussões sobre questões sociocientíficas foi sustentada pelo texto 4. Tais discussões contemplaram os aspectos referentes à definição do termo sociocientífico, às possíveis fontes de evidências para sustentar os enunciados etc. Nesse caso, constatamos que a aprendizagem sobre argumentação nos contextos científico e sociocientífico influenciou o conhecimento das licenciandas no que diz respeito aos materiais instrucionais e às estratégias de ensino, uma vez que elas foram capazes de produzir materiais favoráveis à prática argumentativa em ambos os contextos. Ademais, ao discutir com a professora sobre o desenvolvimento da argumentação a partir de questões científicas, sociocientíficas e sociais, as licenciandas demonstraram entender a diferença entre cada uma dessas questões ao associar as questões científicas à atividade 4 e ao afirmar que a atividade 3 não poderia ser considerada científica e nem sociocientífica, pois para a sua resolução não era necessário mobilizar conhecimentos específicos (aula 8, Quadro 1).

Durante o processo de ensino explícito de argumentação, as licenciandas também tiveram duas oportunidades de planejar aulas simuladas envolvendo argumentação. A existência das simulações e de seus planejamentos permitiu a elas discutir sobre a proposição de materiais adequados ao ensino envolvendo argumentação, além de praticar a elaboração de materiais consistentes com essa proposta de ensino. Dessa forma, a vivência do planejamento e da condução de aulas simuladas influenciou seus conhecimentos sobre materiais instrucionais. Uma evidência dessa influência é fato de as licenciandas terem elaborado materiais mais autênticos nas aulas simuladas finais (aulas 25, 26 e 27, Quadro 1) do que nas primeiras aulas simuladas (aulas 11 e 12, Quadro 1). Isto porque, para a produção dos materiais utilizados na primeira aula simulada, as licenciandas se basearam nas atividades apresentadas pela professora durante as aulas. Por outro lado, na segunda simulação elas elaboraram materiais desvinculados dos materiais utilizados na disciplina e demonstraram compreensão dos conhecimentos sobre argumentação. Por exemplo, para a primeira aula simulada (aula 11, Quadro 1), Letícia e Gisele confeccionaram uma atividade cujas questões favoreciam o trabalho com as capacidades argumentativas de formular argumentos alternativos, contra-argumentos e refutações, tal como proposto pela professora na atividade 4. Por outro lado, na segunda aula simulada (aula 27, Quadro 1), Letícia e Lara construíram uma 
atividade de cunho científico, a qual solicitava aos alunos, principalmente, a apresentação de evidências e justificativas em suas respostas. Nesse caso, é importante ressaltar que a professora utilizou, em sala, materiais que solicitavam a mobilização de evidências e justificativas, mas, diferente do que aconteceu na primeira situação de aula simulada, as licenciandas não mantiveram a estrutura da atividade. Na segunda aula simulada (aula 27, Quadro 1), Letícia e Lara usaram a ideia de trabalhar com as evidências e justificativas, algo importante para o ensino pautado em argumentação e, a partir disso, confeccionaram um material autêntico.

Além disso, o fato de a professora solicitar às licenciandas a apresentação de aulas simuladas contribuiu para que elas tivessem oportunidade de mobilizar seus conhecimentos de argumentação atuando como docentes em contextos de ensino. Apesar de se tratar de contextos simulados, as licenciadas tiveram oportunidades de: conduzir uma situação argumentativa, trabalhando com as evidências experimentais; alinhar as evidências e justificativas à conclusão; engajar os 'alunos' em discussões sobre as diferentes ideias; além de vivenciar dificuldades relativas ao ensino de ciências envolvendo argumentação. Por exemplo, em sua aula simulada (aula 26, Quadro 1), Gisele teve oportunidade de apresentar aos 'alunos' as evidências relacionadas ao fenômeno investigado e utilizá-las para dar suporte às afirmativas científicas. Além disso, naquela situação, ela pode lidar tanto com as evidências que havia selecionado quanto com as evidências apresentadas pelos 'alunos'.

\section{Considerações finais}

Em relação aos aspectos metodológicos que fundamentaram o ensino explícito de argumentação, apontamos que o fato de as licenciandas terem vivenciado situações argumentativas influenciou o desenvolvimento de seus conhecimentos relativos à argumentação. Isto porque elas tiveram oportunidades de: (i) observar e discutir as ações da professora formadora enquanto mediadora de situações argumentativas; (ii) mobilizar seus conhecimentos de argumentação em situações simuladas de ensino; (iii) trabalhar com materiais favoráveis à prática argumentativa; e (iv) discutir sobre os elementos referentes à argumentação mobilizados nas situações vivenciadas.

Mais especificamente, a partir dos elementos elencados no modelo conhecimento para ação docente em argumentação, destacamos que a vivência de situações argumentativas influenciou principalmente o desenvolvimento dos conhecimentos de: (i) evidências; (ii) justificativas; (iii) estratégias de ensino; (iv) ações favoráveis ao ensino por argumentação; (v) materiais instrucionais que podem favorecer a criação de situações argumentativas. Porém, ressaltamos que uma limitação dessa proposta metodológica se refere à inexistência de momentos específicos destinados à reflexão sobre as aulas simuladas. Esses momentos poderiam favorecer a reflexão das licenciandas sobre suas próprias ações ao conduzir situações argumentativas e as dificuldades enfrentadas, podendo potencializar as influências do ensino explícito de argumentação no desenvolvimento das habilidades para conduzir situações argumentativas em sala de aula. Além disso, eles poderiam proporcionar discussões (por exemplo, sobre como contornar as dificuldades enfrentadas naquele momento) que poderiam contribuir para a formação das licenciandas.

No que diz respeito as influências do ensino explícito no desenvolvimento dos conhecimentos docentes em argumentação das licenciandas, ressaltamos que o uso do modelo 
conhecimento para ação docente em argumentação contribuiu para a análise dos dados pois, baseado nos elementos apresentados no mesmo, foi possível estabelecer categorias de conhecimento em argumentação e, a partir disso, buscar as influências do ensino explícito no desenvolvimento de cada um dos aspectos de conhecimento docente em argumentação. Destacamos que, visando identificar as contribuições metodológicas do programa de formação no desenvolvimento dos aspectos apresentados no modelo, ao realizarmos a análise observamos que as contribuições não eram restritas a apenas um deles. Em outras palavras, o ensino explícito de argumentação ocorreu de forma dinâmica, de tal maneira que as ações da professora influenciaram, ao mesmo tempo, o desenvolvimento de mais de um dos aspectos de conhecimentos docentes em argumentação das licenciandas. Por exemplo, os momentos de socialização das respostas das atividades influenciaram tanto os conhecimentos das licenciandas na dimensão pedagógica (como no caso em que Maria reconheceu a importância de haver um momento de discussão das respostas para que ela pudesse tomar consciência de seus conhecimentos), quanto na dimensão conceitual, pois a partir da discussão em sala, a licencianda pode discutir o seu entendimento sobre evidência e justificativa com as colegas e com a professora. Portanto, reconhecemos que o modelo conbecimento para ação docente auxilia na identificação dos aspectos importantes a serem contemplados no ensino de argumentação na formação de professores. Porém, salientamos que esse ensino deve ocorrer de forma orgânica, evitando a fragmentação do conhecimento docente em argumentação uma vez que, em sala de aula, o professor precisa saber relacionar todos esses aspectos para que possa ensinar ciências a partir da promoção e condução de situações argumentativas.

Zembal-Saul (2009) defende que os professores em formação inicial devem ter oportunidades de aprender conceitos científicos de maneira coerente com a forma como eles devem ensinar, a fim de desenvolver práticas pedagógicas adequadas a tal perspectiva de ensino. De forma análoga, consideramos importante que os licenciandos tenham oportunidades de vivenciar situações argumentativas para que possam desenvolver suas práticas pedagógicas favoráveis à argumentação e tomar consciência do papel do professor na construção e mediação das situações argumentativas. Embora essas experiências possam ser proporcionadas tanto por uma abordagem explícita quanto implícita, consideramos importante que professores em formação inicial vivenciem o ensino explícito de argumentação para que tenham oportunidade de desenvolver tanto seus conhecimentos sobre argumentação em si (isto é, conhecimentos sobre a estrutura básica de um argumento e sobre situações argumentativas) quanto conhecimentos pedagógicos relativos a esta perspectiva de ensino (isto é, desenvolver seus conhecimentos sobre estratégias de ensino, materiais instrucionais e habilidades para conduzir situações argumentativas). Isto porque a simples vivência de uma situação de ensino argumentativo não garante que licenciandos tomem consciência sobre as ações adotadas pelo professor que podem favorecer a prática argumentativa no contexto de ensino. Em outras palavras, os futuros professores que vivenciam um ensino implícito de argumentação podem se tornar bons argumentadores e reconhecerem a importância da prática argumentativa no ensino, mas podem enfrentar grandes dificuldades relacionadas a como inserir ou favorecer a argumentação em sala de aula, uma vez que não vivenciaram discussões nesse sentido.

As discussões realizadas nesse trabalho fomentam discussões em uma área ainda pouco explorada: o papel da argumentação na formação inicial de professores. Diferente dos demais trabalhos que têm discutido as contribuições dos programas de formação inicial em argumen- 
tação no desenvolvimento dos conhecimentos de argumentação dos professores (por exemplo, OZDEM et al., 2013 e ZEMBAL-SAUL, 2009), discutimos como os aspectos metodológicos influenciaram esse desenvolvimento. Tal discussão é importante, pois chama atenção para o papel do contexto, isto é, das condições de aprendizagem disponibilizadas aos licenciandos, nas discussões sobre os conhecimentos relacionados à argumentação desenvolvidos por eles - o que pode iluminar as discussões no que diz respeito à estruturação de programas de formação de professores.

Nesse sentido, uma importante contribuição da metodologia adotada no ensino explícito de argumentação aqui estudado se refere ao fato de as licenciandas terem oportunidades de aprender a partir de suas experiências com atividades de caráter argumentativo. No contexto aqui analisado, elas tiveram a oportunidade de vivenciar um ensino no qual os conhecimentos conceituais de argumentação estavam associados aos conhecimentos sobre como inserir argumentação em sala de aula. Entendemos que esse tipo de aprendizagem possa contribuir para a transposição dos conhecimentos pedagógicos desenvolvidos durante a formação inicial para situações de ensino futuras, uma vez que os licenciandos podem desenvolver conhecimentos sobre o que é importante ensinar aos alunos sobre argumentação e como favorecer esse ensino em sala de aula.

Como enfatizado anteriormente, os resultados desse trabalho podem contribuir para a estruturação de programas de formação inicial de professores em argumentação ao apontar aspectos metodológicos que influenciaram o desenvolvimento dos conhecimentos de argumentação das futuras professoras. Essa contribuição é ainda mais relevante no contexto nacional, no qual há uma dicotomia entre os Parâmetros Curriculares Nacionais (BRASIL, 2002), documento que norteia o ensino básico, e o que é desenvolvido nos cursos de formação de professores. Isto porque, embora os Parâmetros Curriculares apontem as competências que os alunos devem desenvolver ao longo do ensino básico, no contexto da formação inicial não há documentos oficiais que apontem quais conteúdos devem ser explorados nas disciplinas pedagógicas específicas dos cursos de Licenciatura para que os professores possam ter condições de favorecer o desenvolvimento de tais competências. Então, a seleção dos conteúdos específicos da área de Ensino de Química fica a cargo e à mercê do interesse e disponibilidade dos professores formadores. Logo, julgamos que esse estudo pode contribuir para a estruturação e reestruturação de programas de formação inicial de professores de Química, uma vez que ressalta a importância de proporcionar aos licenciandos oportunidades de: (i) vivenciar ambientes argumentativos e refletir sobre essas experiências; (ii) conhecer, trabalhar com, e desenvolver materiais que sejam adequados ao ensino na perspectiva da argumentação; e (iii) aplicar seus conhecimentos pedagógicos relativos à argumentação, tais como selecionar estratégias de ensino que favoreçam a ocorrência de argumentação em sala de aula, engajar alunos em discussões sobre seus pontos de vistas, mobilizar evidências e justificativas para os conhecimentos científicos trabalhados em sala etc. em situações simuladas. Além disso, apontamos a necessidade de futuros programas de formação em argumentação disponibilizarem momentos específicos para a reflexão dos licenciandos sobre suas experiências com as aulas simuladas.

Outra contribuição para a estruturação dos programas de formação inicial de professores em argumentação se relaciona à organização do programa investigado nesse trabalho. Inicialmente, as licenciandas desenvolveram conhecimentos sobre a natureza da prática argumentativa, isto é, 'o que conta' como uma evidência em determinado contexto, o significado de justificativa e das habilidades argumentativas etc. Depois elas utilizaram esses conhecimentos 
nas situações simuladas de ensino, isto é, desenvolveram conhecimentos práticos sobre aspectos pedagógicos relacionados ao ensino baseado em argumentação. Em outras palavras, as licenciandas aprenderam sobre argumentação e refletiram sobre essa aprendizagem a partir de suas experiências como alunas e das ações da professora formadora ao conduzir o ensino, além de terem oportunidades de mobilizar tais conhecimentos em situações práticas que também contribuíram para o desenvolvimento dos conhecimentos sobre a natureza da prática argumentativa. Logo, as principais implicações desse trabalho se relacionam a: apontar a necessidade de os programas de formação de professores em argumentação oportunizarem a aprendizagem sobre a natureza da prática argumentativa; e indicar que estes devem ir além do conhecimento teórico sobre a argumentação para que os futuros professores possam desenvolver conhecimentos pedagógicos relativos à perspectiva de ensino pautada em argumentação e, ao mesmo tempo, aperfeiçoar seus conhecimentos teóricos.

Tendo em vista, a importância da prática argumentativa nas salas de aulas de ciências e o papel do professor frente à criação e condução das situações argumentativas no contexto de ensino, importantes questões de pesquisa associadas à prática do professor emergem deste trabalho:

- O programa de ensino explícito de argumentação vivenciado por esses professores influencia suas práticas docentes em situações reais de ensino? Em caso afirmativo, há relação entre os aspectos metodológicos adotados durante a formação inicial e os aspectos metodológicos propostos pelo professor nas salas de ciências da educação básica?;

- Os professores que vivenciaram o ensino explícito de argumentação são capazes de promover situações argumentativas em sala de aula? Em caso afirmativo, há relação entre os conhecimentos sobre a natureza da prática argumentativa desenvolvidos na formação inicial e a capacidade desses professores de promover situações argumentativas?

Investigar a relação entre o programa de formação inicial e o desenvolvimento dos conhecimentos docentes em argumentação, o qual inclui organizar e planejar um ensino na perspectiva da argumentação, é importante para que se possa ter dimensão das reais influências da metodologia adotada nos cursos de formação inicial na prática dos professores. Por exemplo, professores recém-formados podem optar por trabalhar de uma forma semelhante à vivenciada por eles para engajar os alunos em argumentação, ou podem se basear nas reflexões propostas pelo professor formador para sustentar suas próprias reflexões no contexto de ensino, ou, ainda, a partir das situações vivenciadas podem elencar quais aspectos de argumentação são mais importantes de serem trabalhados na educação básica. Assim, investigar questões como estas pode dar suporte à análise de possíveis contribuições ou limitações da metodologia adotada no ensino de argumentação durante a formação inicial para o desenvolvimento dos conhecimentos dos professores sobre como ensinar ciências nessa perspectiva.

\section{Agradecimentos}

Ao Conselho Nacional de Desenvolvimento Científico e Tecnológico (CNPq). 
Ibraim, S. S.; Justi, R.

\section{Referências}

BRASIL. Ministério da Educação. PCN + ensino médio: orientações educacionais complementares aos parâmetros curriculares nacionais: ciências da natureza, matemática e suas tecnologias. Brasília, 2001.

Parâmetros curriculares nacionais. Brasília, 2002.

ERDURAN, S.; PABUCCU, A. Bonding chemistry and argument: teaching and learning argumentation through chemistry stories. Bristol: University of Bristol, 2012.

GIERE, R. N. A new framework for teaching scientific reasoning. Argumentation, Dordrecht, v. 15, n. 2, p. 21-33, 2001.

GILBERT, J. K. Models and modelling: routes to a more authentic science education. International Journal of Science and Mathematics Education, Taiwan, v. 2, n. 2, p. 115-130, 2004.

IBRAIM, S. S.; JUSTI, R. Teachers' knowledge in argumentation: contributions from an explicit teaching in an initial teacher education programme. International Journal of Science Education, London, v. 38, n. 12, p. 1996-2025, 2016.

JIMÉNEZ-ALEIXANDRE, M. P. 10 ideas clave: competencias en argumentación y uso de pruebas. Barcelona: Graó, 2010.

JIMÉNEZ-ALEIXANDRE, M. P.; PEREIRO MUÑOZ, C. Knowledge producers or knowledge consumers?: argumentation and decision making about environmental management. International Journal of Science Education, London, v. 24, n. 11, p. 1171-1190, 2002.

JIMÉNEZ-ALEIXANDRE, M. P. et al. Actividades para trabajar el uso de pruebas y la argumentación en ciencias. Santiago de Compostela: Universidad de Santiago de Compostela, 2009.

KUHN, D. The skill of argument. New York: Cambridge University, 1991.

MCNEILL, K. L.; PIMENTEL, D. S. Scientific discourse in three urban classrooms: the role of the teacher in engaging high school students in srgumentation. Science Education, Hoboken, v. 94, n. 2, p. 203-229, 2010.

NATIONAL RESEARCH COUNCIL. A framework for K-12 science education: practices, crosscutting concepts, and core ideas. Washington: National Academy of Sciences, 2012.

OSBORNE, J.; ERDURAN, S.; SIMON, S. Ideas, evidence \& argumentation in science education: CPD pack for teacher professional development. London: King's College London, 2004.

OZDEM, Y. et al. The nature of pre-service science teachers' argumentation in inquiryoriented laboratory context. International Journal of Science Education, London, v. 35, n. 15, p. 2559-2586, 2013. 
Influências de um ensino explícito de argumentação ...

SAMPSON, V. et al. Writing to learning to write during the school science laboratory: helping middle and high school student develop argumentative writing skills as they learn core ideas. Science Education, Hoboken, v. 97, n. 5, p. 643-670, 2013.

SIMON, S.; ERDURAN, S.; OSBORNE, J. Learning to teach argumentation: research and development in the science classroom. International Journal of Science Education, London, v. 28, n. 2-3, p. 235-260, 2006.

TOULMIN, S. The uses of argument. New York: Cambridge University Press, 1958.

ZEMBAL-SAUL, C. Learning to teach elementary school science as argument. Science Education, Hoboken, v. 93, n. 4, p. 687-719, 2009.

ZOHAR, A. Science teacher education and professional development in argumentation. In: ERDURAN, S.; JIMÉNEZ-ALEIXANDRE, M. P. (Ed.). Argumentation in science education: perspectives from classroom-based research. Dordrecht: Springer, 2008. p. 245268.

Artigo recebido em 25/02/2016. Aceito em 21/02/2017.

Endereço para contato: UFMG, Faculdade de Educação, PPGE, Avenida Antônio Carlos, 6627, Pampulha, 31270-90, Belo Horizonte, MG, Brasil. 
